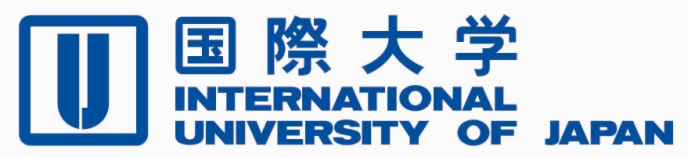

Economics \& Management Series

EMS-2011-17

\title{
Health Insurance Reform and Economic Growth: Sim- ulation Analysis in Japan
}

\section{Toshihiro Ihori}

The University of Tokyo

Ryuta Ray Kato

International University of Japan

\author{
Masumi Kawade \\ Nihon University
}

Shun-ichiro Bessho

Hitotsubashi University

September 2011

IUJ Research Institute

International University of Japan

These working papers are preliminary research documents published by the IUJ research institute. To facilitate prompt distribution, they have not been formally reviewed and edited. They are circulated in order to stimulate discussion and critical comment and may be revised. The views and interpretations expressed in these papers are those of the author(s). It is expected that the working papers will be published in some other form. 


\title{
Health Insurance Reform and Economic Growth: Simulation Analysis in Japan *
}

\author{
Toshihiro Ihori ${ }^{\dagger}$ \\ Masumi Kawade ${ }^{\S}$ \\ Ryuta Ray Kato \\ Shun-ichiro Bessho
}

September 12, 2011

\begin{abstract}
This paper evaluates the drastic reforms of Japanese public health insurance initiated in 2006. We employ a computable general equilibrium framework to numerically examine the reforms for an aging Japan in the dynamic context of overlapping generations. Our simulation produced the following results: First, an increase in the co-payment rate, a prominent feature of the 2006 reform, would promote economic growth and welfare by encouraging private saving. Second, the ex-post moral hazard behavior following the increase in co-payment rates, however, reduces economic growth. Third, Japan's trend of increasing the future public health insurance benefits can mainly be explained by its aging population, and increasing the co-payment rate does little to reduce future payments of public health insurance benefits. Fourth, the effect on future economic burdens of reducing medical costs through efficiencies in public health insurance, emphasis on preventive medical care, or technological progress in the medical field is small. Finally, a policy of maintaining public health insurance at a fixed percentage of GDP will require reducing public health insurance benefits, perhaps up to $45 \%$ by 2050 . Such a policy also reduces economic growth until approximately 2035. Our simulation indicates that the reform does not significantly reduce future public health insurance benefits, but it can enhance economic growth and welfare by encouraging private saving.
\end{abstract}

Keywords: public health insurance; Japan; national medical expenditure; economic growth; aging population; dynamic CGE model

JEL Classification: C68, D58, E17, E62, H51, H55, H62,I18, O40

*The Grants-in-Aid for Scientific Research of Scientific Research C (No. 19530294) by Japan Society for the Promotion of Science (JSPS) are acknowledged. We are solely responsible for any remaining errors.

${ }^{\dagger}$ University of Tokyo.

${ }^{\ddagger}$ International University of Japan.

$\S$ Nihon University.

"Hitotsubashi University, 


\section{Introduction}

Japan has undergone one of the most drastic reforms of public health insurance since the present system was launched. Begun in 2006, several reforms have been implemented gradually and necessarily, because Japan's public health insurance program could be unsustainable as its population ages. Since medical expenditure by people 65 and older are more than half of Japan's total medical expenditure ${ }^{1}$, the reform particularly aims at decreasing medical expenditure by the elderly. This study investigates the effect of the 2006 reform on economic growth of Japan by simulating scenarios involving an aging populace in a dynamic context of overlapping generations in a general equilibrium framework.

Japan's current ratio of the national medical expenditure to GDP exceeds $8 \%$ and is growing faster than the economy. Their effect on GDP is no longer negligible, and trends imply that their effect on economic growth could increase in future. Detailed numerical examination of the reform's effects on growth is warranted.

Another factor motivating reform is the prospect that future generations would pay higher premiums for public health insurance, if the current program is maintained. This study differs from previous studies in numerically exploring and evaluating intergenerational effects of reform through a multi-period overlapping-generations model developed by Auerbach and Kotlikoff (1983) within a general equilibrium framework ${ }^{2}$.

It has been empirically observed that changes in co-payments, a prominent feature of the 2006 reform, have little effect ${ }^{3}$, and empirical studies using micro-data have found little evidence of ex-post moral hazard in individual behavior. However, the literature has evaluated the behavioral consequences of changing co-payment rates within a partial equilibrium framework and left unexplored the effects on the macro-economy and on the welfare

\footnotetext{
${ }^{1}$ About $30 \%$ of the total national medical expenditure was spent by the age group of 75 and over in year 2006.

${ }^{2}$ Although many empirical studies on the Japanese health care system have been conducted, almost all use a partial equilibrium framework. Japan's health care system has not been examined within a general equilibrium framework. See Ii and Bessho (2006) for the existing empirical literature.

${ }^{3}$ See Ii and Bessho (2006), which mainly surveyed the empirical literature where the micro data were used.
} 
of disparate generations. This study numerically examines, within a general equilibrium framework, the effect of changing the co-payment rate over time on the macro-economy and intergenerational welfare.

The reform seeks to reduce national medical expenditure by improving efficiency in providing medical services and by urging practitioners to augment preventive care. As Hiroi (1994) pointed out, however, technological advances might induce increases in national medical expenditure. Thus, this study simulates the effects of increases and decreases in national medical expenditure via reform. Some advocate limiting the growth rate of Japan's national medical expenditure to the rate of economic growth. This argument is also evaluated numerically.

Our simulation results indicate that the reform is not particularly effective in reducing future national medical expenditure. On the other hand, an increase in the co-payment rate would promote economic growth and welfare by encouraging private saving. However, the magnitude of the effect on economic growth is not large. The effect on future economic burdens of reducing medical costs through efficiencies in public health insurance, emphasis on preventive medical care, or technological progress in the medical field is also small. These results suggest that Japan's trend of increasing the future public health insurance benefits can mainly be explained by its aging population.

This paper is organized as follows: The next section introduces the Japanese health care system. Section 3 explains reforms initiated in 2006. Section 4 simulates the effect on economic growth and burdens of changes in key instruments by incorporating population aging. Section 5 concludes. 


\section{The Japanese Health Care System}

The demand side of Japan's health care system is characterized by guaranteed free access to services at any medical institution and compulsory coverage of all age and income groups ${ }^{4}$.

Free access implies that people can receive consultations, treatments, and procedures at any medical institution without referrals, and patients can decide where and when they seek medical services.

Universal and compulsory coverage means everyone must contribute to an insurer consisting of the public health insurance ${ }^{5}$, based on their employment ${ }^{6}$. It consists of several insurers $^{7}$, as shown in Figure 1. Japanese public health insurance can be categorized according to type of employment, employment-based health insurance, and other types of insurance. Persons not insured under an employment-based policy are insured by the Local Governments' National Health Insurance (Shichoson Kokuho). Some self-employed persons have individual public health insurance through networks serving persons in similar professions such as medical doctors and barbers; such insurance is integrated into the Unions of National Health Insurance (Kokumin Kenko Hoken Kumiai). Self-employed persons not insured by a provider affiliated with Unions of National Health Insurance are insured by Local Governments' National Health Insurance. Together, Local Governments' National Health Insurance and the Unions of National Health Insurance are called National Health Insurance (Kokuho). Employees' health insurance is of four types: Seamen's Insurance, Mutual Aid Associations, Insurance by National Federations of Health Insurance Societies, and Insurance by Japan Health Insurance Association. Table 1 shows several insurers comprising the public health insurance system.

\footnotetext{
${ }^{4}$ There is a separate public health insurance for long-term care (Kaigo Hoken). Since persons of age 40 and over also must contribute to long-term care insurance, Japanese public health insurance can be interpreted as being compulsory and universal. Persons 65 and older are category 1 insured and are entitled to long-term care through public long-term care insurance. Persons of age 40 to 64 occupy category 2. They usually are ineligible to receive public long-term care, but they must contribute to the system.

${ }^{5}$ All dependents and retired persons are also insured.

${ }^{6}$ The number of insured persons who have not paid the compulsory premium has been increasing. However, this study does not discuss that issue.

${ }^{7}$ See also Tokita (2002) for detailed explanation of the Japan's health care system.
} 
Almost all medical services are covered by public health insurance ${ }^{8}$, and the costs of medical services, including drugs prescribed at medical institutions, is financed by premiums paid for public health insurance, public funds (taxes), and co-payments. The co-payment rate depends on age and not on the differences among insurers. ${ }^{9}$. All insured persons can obtain almost all medical services by paying a co-payment at any medical institution when they receive treatment.

In terms of public health insurance for the elderly, the government introduced a system in 2008 to address the unequal distribution of financial burdens among different bodies consisting of the public health insurance. Figure 2 shows the new public health insurance for the elderly. In general, employees purchase their own insurance through premiums paid during their working lives ${ }^{10}$. After retirement, they fall under National Health Insurance. People usually require more medical services as they age, implying that National Health Insurance acquires more "costly" persons who did not contribute to it during their careers. Hence the government has divided persons 65 and older into two groups shown in Figure 2. The first includes persons aged 65 to 74 . Persons in this group retain their previous insurance after retirement, but the biased distribution of financial burden is adjusted among different insurers according to the ratio of the number of the elderly to the total number of persons each insurer insures. Every person 75 and older moves to a new public health insurance called Choju Iryo Seido, as discussed in Section 3.

The supply side of Japanese health care can be described as fee-for-service ${ }^{11}$. Japan's medical fee system (Shinryo-hoshu Seido) is based on government-allotted points specified

\footnotetext{
${ }^{8}$ For instance, normal births and cosmetic surgeries are not covered by public health insurance. Many expensive medical services also are excluded from coverage.

${ }^{9}$ Current co-payments range from $20-30 \%$. The rate depends on different insurers, although the range is regulated by law.

${ }^{10}$ As explained in Section 4.2.3, public health insurance premiums are usually paid on a monthly basis, as a short-term contribution to the social insurance program, together with a contribution to the public pension. The contribution to the public pension is called a long-term contribution in the program. Social insurance consists of several provisions; public health insurance and the public pension are Japan's primary social insurance schemes.

${ }^{11}$ Several hospitals have moved to the prospective reimbursement scheme with Diagnosis Procedure Combinations (DPC), Japan's version of diagnosis-related grouping (DRG). However, many medical services are still based on the fee-for-service scheme.
} 
for all treatments, procedures, and drugs covered by public health insurance. Payment for covered services is made to medical institutions based on these points. Points include income of physicians generated by the provision of medical services ${ }^{12}$. Since almost all medical services are covered by public health insurance, government essentially determines prices for medical services, including payments to physicians, although some services, such as yearly check-ups, are provided in private markets with prices determined apart from regulated prices. This implies there are financial incentives among hospitals and physicians to use more profitable items if the wholesale prices are lower than the regulated prices.

Figure 3 shows the payment procedure. In practice, hospitals or physicians do not file claims directly with insurers. They first file with the local fund on the basis of points allocated for the services provided. The local fund examines their claims and reports the amount to each insurer ${ }^{13}$. Insurers pay that amount to the local fund, which then pays this amount to the hospitals and physicians. This implies that insurers have no right to investigate the medical services provided by hospitals and physicians. Tokita (2002) pointed out that their weak investigative power has resulted in higher national medical expenditure.

The difference in the employment structure of physicians also characterizes the supply side of the Japanese health care system. Physicians are self-employed or hospital-employed, and Japan's medical fee system regards them equally, although their sources of income are different. Hospital-employed physicians are usually paid a fixed salary, whereas self-employed physicians' income depends on their choice of working hours, treatments, and procedures provided to patients. Although insured patients can visit any medical institution, they customarily consult self-employed physicians for primary care, and self-employed physicians essentially function as gatekeepers.

\footnotetext{
${ }^{12}$ One point is equivalent to 10 Japanese yen. For example, a physician who provides treatment assessed at 1,000 points can claim 10,000 Japanese yen minus the patient's co-payment to the insurer.

${ }^{13}$ The local fund sometimes returns claims to hospitals and physicians for recalculation after investigation. However, the huge number of claims presented to the fund every month makes it unlikely works to detect all erroneous claims.
} 


\section{The Reform}

One main purpose of the reform is to reduce the national medical expenditure. As shown in Figure 4, per capita national medical expenditure and the ratio of national medical expenditure to GDP have been rising. A major impetus for reform is Japan's rapidly aging population, as shown in Figure 5. Figure 6 classifies the 2006 national medical expenditure by age group. In 2006, expenditure by persons 65 and older was $51.6 \%$ of the total national medical expenditure. For patients 75 and older, the ratio was 21.9\%. Both figures predict substantial increases in national medical expenditure as the population ages.

Specific reforms include (1) emphasizing preventive medical care, (2) improving efficiency in providing health services, (3) instituting a new public health insurance program for the elderly, (4) increasing co-payment rates for the elderly, (5) integrating several public health insurers, and (6) altering the medical fee system. Each is explained as follows.

\subsection{Importance of Preventative Medical Services}

The reform included proposals encouraging medical institutions and physicians to provide more preventive care in an effort to reduce national medical expenditure. Several concrete plans to guide medical institutions and physicians for providing more preventive medical services were listed in the reform.

\subsection{Efficiency in the Public Health Insurance}

Data have demonstrated positive correlations between the number of beds devoted to acute care and national medical expenditure. Data also find positive correlation between average length of stay in acute care and national medical expenditure. The reform modified the point system to reduce the average length of stay. To provide medical services more efficiently while maintaining universal access to care, the reform introduced the provision of medical services at the prefecture level (Todohuken) rather than the national level. This implies that quality 
of medical services, including the level of premium, could differ among provinces. The plan to achieve efficient provision follows the Plan-Do-Check-Act method, which will be evaluated comprehensively in 2012 .

\subsection{New Public Health Insurance for the Elderly}

Responding to projections of a rapidly aging populace, a new public health insurance for those of age 75 and older has been launched in addition to existing insurance. Called Choju Iryo Seido, this newly introduced insurance is financed through premiums paid by those 75 and over (10\%), premiums by persons insured with other insurers (40\%), and a public fund (50\%). The $40 \%$ funded by premiums paid to other insurers is essentially an intergenerational transfer.

\subsection{Increase in the Co-payment Rate}

The 2006 reform modified co-payment rates, which are determined by patients' ages, not their insurers, as shown in Table 2. In particular, the 2006 reform increased co-payment rates and scheduled an April 2009 increase from 10\% to 20\% in co-payment rates for people aged 70 to $74^{14}$. In addition to regular insurance premiums, the elderly must pay co-payments when they receive treatment.

\subsection{Integration of Several Insurers}

Table 1 shows current existing insurers of the public health insurance. Several are financially weak. In particular, the integration of National Health Insurance, National Federation of Health Insurance Societies, and Japan Health Insurance Association has been considered.

\footnotetext{
${ }^{14}$ It has already increased to $20 \%$.
} 


\subsection{Reform of the Medical Fee System}

The Japanese medical fee point system is modified every two years. Points for several medical services and medical drugs have been modified since 2006, and the total number of points was decreased by $3.16 \%$ in 2006 . Hoping to reallocate medical resources, the modification was imposed to meet the strained budget of the public health insurance system. Since the fee system regulates prices for covered services, the modification of points deserves special notice.

A key motivation for the reform is that rapid aging of Japan's population will further burden the public health insurance program. Therefore, accurately predicting the future population is important in evaluating the long-run effectiveness of the reform. The next section explains the model we used in simulation scenarios that incorporate realistic demographic estimates.

\section{Simulation Analysis}

The effect of the reform on economic growth as well as welfare is simulated in the long-run, by explicitly taking into account an aging population in the future. Our simulations employ a multi-period overlapping generations model developed by Auerbach and Kotlikoff (1983) within a general equilibrium framework. Taxes, a public pension scheme, and a public health insurance scheme are incorporated into the model to investigate the effect of the reform of the existing Japanese system. The model consists of the household, the private firm, and the government. The government runs the general account and the social insurance account. The social insurance account consists of a pay-as-you-go public pension scheme and a public health insurance scheme. In order to capture the realistic demographic change in an aging Japan, the actual population data as well as the latest estimate of a future population are both used. 


\subsection{The Model}

The representative household is assumed to optimize its intertemporal consumption through its lifetime, taking the wage rate, the interest rate, and its own survival rates as given. The tax system, the public pension scheme, and the public health insurance scheme are also assumed to be taken as given by the household. The household is assumed to obtain its wage income by supplying labor inelastically until it retires, and once it retires it never returns to the labor market. There are no altruistic bequest motives and Ricardian equivalence does not hold.

The firm is assumed to maximize its profit by taking the wage rate and the interest rate as given. The wage rate and the interest rate are determined in each fully competitive factor market in equilibrium.

The government sector is assumed to collect taxes from the household, and also to issue government bonds in order to fulfill its budget constraint. The government sector has its general account as well as the social insurance account. In order to capture the realistic aspect of its accounts, the government is assumed to have transfers from the general account to the social insurance account. The social insurance account is assumed to consist of a payas-you-go public pension scheme and a public health insurance scheme. The government is also assumed to accumulate a public pension fund.

It is assumed that there is no private life insurance, and thus there is no mechanism for the household to hedge the risk of dying in each period. Since the household is assumed to have no bequest motives, this assumption implies that the household leaves an accidental bequest when it dies. However, it is also assumed that there is no uncertainty in the whole economy in terms of the size of each generation, and thus there is no uncertainty in the total (aggregate) amount of bequests inherited in each period. 


\subsubsection{The Household}

The household appears in the economy at age 20 as a decision maker. Although the household faces uncertainty regarding its death in each period, it dies with certainty at the end of its age of 99 if it is alive until age 99. Denote the survival rate of generation $i$ at time $t$ by $q_{i, t}$. There is assumed to be no uncertainty regarding the size of the total population in each period.

The household is assumed to maximize its expected lifetime utility with respect to its own consumption. The household's expected lifetime utility of generation $i$ is given by ${ }^{15}$

$$
E\left[V_{i}\right]=\sum_{t=i}^{i+79} q_{i, t}(1+\delta)^{-(t-i)} \frac{\left(c_{i, t}-m_{i, t}\right)^{1-\rho}}{1-\rho}
$$

where $c_{i, t}, \delta$, and $\rho$ denote consumption at time $t$, the discount rate of time, and the index of relative risk aversion, respectively. $m_{i, t}$ represents a subsistence level of consumption at age $t-i$, and it is the minimum level of consumption at which the household can be "healthy" in the sense that it can only enjoy its consumption in excess of $m_{i, t}$. Note that the net amount of consumption over $m_{i, t}$ only generates utility. $m_{i, t}$ can be interpreted as the medical expenditure measured in a consumption good $c$ to be healthy in each period, while consumption of medical services is not considered explicitly in this paper ${ }^{16}$. In order to simulate the effect of the change in the medical expenditure in the subsequent sections, it is simply assumed that $m_{i, t}$ is exogenously given. As pointed out by several studies ${ }^{17}$, the per capita medical expenditure by age shows a U-shaped pattern, and $m_{i, t}$ is given to be U-shaped in the simulations. As explained in the previous section, many medical services are covered by the public health insurance in the current system. Due to the U shape of the medical expenditure by age, an aging population results in an increase in the aggregate

\footnotetext{
${ }^{15}$ According to the result by Hayashi (1995), bequest motives are not considered here. Strategic bequest motives are also not considered. Since there is also no uncertainty regarding wage income, a precautionary saving motive for uncertain wage fluctuation is not considered, which was discussed in Horioka and Watanabe (1997).

${ }^{16}$ See Johansson (2000) for the case where the household optimally chooses the amount of medical services.

${ }^{17}$ See Reinhardt (2000) for instance.
} 
amount of benefits provided through the public health insurance, although it is assumed that the age pattern of $m_{i, t}$ does not change in the future.

The budget constraint of the $s$-year-old household of generation $i$ at time $t$ is given by

$$
\begin{aligned}
a_{i, t} & =\left[1+\left(1-\tau_{r, t}\right) r_{t}\right] a_{i, t-1}+\left(1-\tau_{y, t}-\tau_{p, t}\right) w_{t} e_{i, s}+b_{i, s} \\
& +p s_{i, t}+\left(1-c p_{i, t}\right) m_{i, t}-\left(1+\tau_{c, t}\right) c_{i, t}
\end{aligned}
$$

where $a_{i, t}, r_{t}$, and $e_{i, s}$ denote its assets of generation $i$ at the end of period $t$, the interest rate, and a measure of effective labor, respectively ${ }^{18}$. The household supplies labor inelastically until it retires, and once it retires, it never comes back to the labor market. $w_{t}$ is the wage rate per efficiency unit of labor, and $w_{t} e_{i, s}$ is pre-tax labor income. All taxes are proportional, and $\tau_{y, t}, \tau_{r, t}$ and $\tau_{c, t}$ denote the wage income tax rate, the interest income tax rate, and the consumption tax rate, respectively. The contribution rate, or the premium rate of the social insurance account is denoted by $\tau_{p, t}$. The social insurance account consists of a public pension scheme as well as a public health insurance scheme, and the total amount of collected contributions or premiums is divided into the two schemes. $p s_{i, t}$ denotes the amount of per capita public pension benefits. $c p_{i, t}$ denotes a co-payment rate, and thus $c p_{i, t} m_{i, t}$ is the total medical expenditure the household has to pay when it receives medical services at medical institutions. $\left(1-c p_{i, t}\right) m_{i, t}$ is the total medical expenditure covered by the public health insurance, and this can be interpreted as the amount of benefits given to the household through the public health insurance when it receives medical services. An ex-post moral hazard problem in the health insurance is not considered in this paper ${ }^{19}$. Denoting the age when the household starts obtaining pension benefits by $R$ and the replacement rate

\footnotetext{
${ }^{18}$ The profile of effective labor follows Kato (2002).

${ }^{19}$ While our model itself does not incorporate the ex-post moral hazard behavior into the framework, the effect of the ex-post moral hazard behavior is investigated in the simulation section by changing $m_{i, t}$ exogenously.
} 
by $\beta_{p}$, the amount of pension benefits the household receives is given by

$$
p s_{i, s}=\left\{\begin{array}{ll}
\beta_{p}\left(\frac{1}{R} \sum_{s=0}^{R-1} w_{t} e_{i, s}\right) & \text { if } t-i \geq R \\
0 & \text { if } t-i<R
\end{array} .\right.
$$

It is assumed that the household contributes to the social insurance scheme from age 20 to age 64 . It is also assumed that there is no private pension market ${ }^{20}$.

Assets held by the household which dies are left as accidental bequests. These accidental bequests are assumed to be redistributed equally to all households alive in each period, which is denoted by $b_{i, s}$ in equation (2).

The first order necessary conditions of the household yield the Euler equation such that

$$
\left(c_{i, t}-m_{i, t}\right)^{-\rho}=\frac{q_{i, t+1}}{q_{i, t}} \frac{1+\left(1-\tau_{r, t+1}\right) r_{t+1}}{1+\delta} \frac{1+\tau_{c, t}}{1+\tau_{c, t+1}}\left(c_{i, t+1}-m_{i, t+1}\right)^{-\rho},
$$

from which the optimal consumption path can be derived once the initial value of consumption is given. In the simulation section, the initial value of consumption is given to satisfy the lifetime budget constraint of the household, so that the optimal consumption path also satisfies the budget constraint.

\subsubsection{The Firm}

The firm is assumed to maximize its profits, taking the wage rate and the interest rate as given. The wage rate and the interest rate are determined in perfectly competitive factor markets in equilibrium. The aggregate private production function is assumed to be CobbDouglas such that

$$
Y_{t}=Z_{t} L_{t}^{\alpha} K_{t}^{1-\alpha}
$$

\footnotetext{
${ }^{20}$ See Iwamoto et al. (1993), Friedman and Warshawsky (1988), and Friedman and Warshawsky (1990) for models which include the private pension market.
} 
where $Y_{t}$ represents aggregate output at time $t, K_{t}$ the aggregate private capital stock, $L_{t}$ aggregate labor supply measured in the effective labor unit. $Z_{t}$ denotes technology of production of the private sector. Assuming that each factor market is perfectly competitive with the above aggregate production function, output is fully distributed to labor and capital.

The first order necessary conditions of the firm yield

$$
\begin{aligned}
& w_{t}=\alpha Z_{t} L_{t}^{\alpha-1} K_{t}^{1-\alpha} \\
& r_{t}=(1-\alpha) Z_{t} L_{t}^{\alpha} K_{t}^{-\alpha}-\delta_{k},
\end{aligned}
$$

where $\delta_{k}$ denotes the depreciation rate for the capital stock.

\subsubsection{The Government Sector}

The government sector consists of a general account and a social insurance account.

Expenditure in the general account includes the general government expenditure and transfers to the social insurance account. Expenditure of the general account is financed by taxes and government bonds. The general government expenditure includes government consumption, government investments, interest payments incurred by government debts, and transfers to the household. Note that these transfers to the household are different from the transfers to the social insurance account.

The social insurance account consists of a public pension account and a public health insurance account. The amount of transfers to the social insurance account from the general account is characterized by $\eta$, which is the ratio of the amount of transfers to the total amount of social insurance benefits. The government sector is assumed to have no particular objective function which it maximizes. The budget constraint of the general account is

$$
\begin{aligned}
G_{t}+\eta S_{t} & =R_{t}+B_{t}-\left(1+r_{t}\right) B_{t-1} \\
R_{t} & =\tau_{c, t} C_{t}+\tau_{y, t} w_{t} L_{t}+\tau_{r, t} r_{t} K_{t}+\tau_{h, t} Q_{t},
\end{aligned}
$$


where $B_{t}, R_{t}$, and $G_{t}$ denote the amount of outstanding government bonds, the total tax revenue, and the total general government expenditure, respectively. The total amount of bequests is represented by $Q_{t}$. Transfers to the social insurance account are denoted by $\eta S_{t}$, where $S_{t}$ is the total social insurance benefits. $\tau_{h, t}$ denotes the inheritance tax rate. In the following simulations only the consumption tax rate is endogenously determined to satisfy the budget constraint over time, and all other tax rates are exogenously fixed at the values of year 2007 .

The budget constraint of the social insurance account and the contribution, or the premium rate, are defined as

$$
F_{t}=\left(1+r_{t}\right) F_{t-1}+\tau_{p, t} w_{t} L_{t}-(1-\eta) S_{t}
$$

where $F_{t}$ is an accumulated public pension fund at the end of period $t$. The total amount of benefits includes public pension benefits and public health insurance benefits. The contribution (premium) rate is determined endogenously in order to satisfy (7), while the realistic value of $F_{t}$ is given exogenously in our simulation analysis.

\subsubsection{Equilibrium}

The equilibrium condition of the capital market in period $t$ is given by:

$$
\sum_{i} N_{i, t} a_{i, t-1}+F_{t-1}=K_{t}+B_{t}
$$

where $N_{i, t}$ is the number of households of generation $i$ in period $t$. The equilibrium condition of the goods market is given by:

$$
Y_{t}=C_{t}+\left(K_{t+1}-\left(1-\delta_{k}\right) K_{t}\right)+G_{t}
$$

Note that the general equilibrium of fully competitive markets is described by these two 
equilibrium conditions in addition to the first order conditions described by (3), (5a), and (5b), where the contribution (premium) rate $\tau_{p, t}$ and the consumption tax rate $\tau_{c, t}$ are also determined endogenously in order to satisfy the budget constraints of the government given by $(6 a),(6 b)$, and (7).

\subsection{Data and Assumptions}

In order to make our simulations as realistic as possible, available actual and projected data have been used together with estimated values of relevant parameters based on the empirical research. The key elements are; demography, government deficits, public pension scheme, public health insurance scheme, and the tax structure. The following assumptions have been made in order to obtain our realistic benchmark model.

\subsubsection{Demography}

The actual population data have been used from 1965 to 2000. Before 1965 the population data were calculated under the assumption that the fertility rate and the mortality rate were the same as in 1965. Regarding population projections, the "medium variant" projections from the latest edition of Projection of Future Population in Japan (Shourai-Jinko-Suikei, 2006) have been used. Life Tables in Kanzen and Seimeihyo and Shourai-Jinko-Suikei (2006) were used to obtain survival rates. Since Projection of Future Population in Japan only gives estimates of the future population until 2105, it has been assumed that the number of births and deaths, and the survival rates after 2105 are fixed at the same levels as those in 2105 .

\subsubsection{Government Deficits}

Until 2007 the actual data from SNA have been used. From 2008, the future sequence of government deficits has been given based on the following assumptions.

Since the average growth rate of the ratio of government debts to GDP (the debt-to-GDP ratio) between 1998 and 2007 was calculated to be 5\%, the growth rate of the debt-to-GDP 
ratio in year 2008 has been assumed to be 5\%. Furthermore, the growth rate of the debtto-GDP ratio from 2009 has been assumed to decrease by $0.5 \%$ every year. This implies that the annual growth rate of the debt-to-GDP ratio from 2009 has been given to be $4.5 \%$, $4.0 \%, 3.5 \%$ so on. Then, it has been assumed that the growth rate of the debt-to-GDP ratio continues to decrease until year 2019, and also that the growth rate of the ratio becomes zero after year 2019. This implies that the debt-to-GDP ratio keeps constant after year 2019, and the constant debt-to-GDP ratio is $150 \%$ as shown in Table 1.

\subsubsection{Social Insurance Scheme}

The social insurance scheme consists of two schemes: the public pension scheme and the public health insurance scheme.

The actual data until 2007 have been used for both schemes. The amount of transfers to the social insurance account from the general account, characterized by $\eta$, and the replacement rate, $\beta_{p}$, were both calculated from SNA. In terms of the contribution (premium) rate, the actual data have also been used until 2007. In Japan's actual system, the public pension contribution (the long-term contribution) and the public health insurance premium (the short-term contribution) are typically collected together as the social insurance contribution. The contribution rate was calibrated in order to satisfy (7), where the amount of the pension fund is exogenously given.

Public Pension Scheme The public pension scheme has been assumed to have the same replacement rate $\beta_{p}$ of year 2007 in the future. In terms of the years before 2007, the actual data have been used in simulations. Regarding the amount of the public pension fund, the actual data have been used until 2007. From 2008, the ratio of the fund to GDP has been assumed to be constant at the same level as that of 2007 .

Public Health Insurance Scheme The actual data have been used until 2007. Based on National Medical Expenditure issued by Japan's Ministry of Health, Labor and Welfare, 
the SNA data have been modified to obtain per capita public health insurance benefits which the household receives every year. Until 2007, the actual per capita benefits have been calculated, and a U-shaped pattern on age similar to Figure 6 has been obtained for simulations. From 2008, the U-shaped pattern of year 2007 has been assumed to continue. This implies that $m_{i, t}$ changes with $s$ but not with generation $i$ from 2008 onward. The growth rate of per capita national medical expenditure has been assumed to be the same as that of technological progress in production given by (4). In terms of the co-payment rate, $c p_{i, t}$, it has been assumed in the benchmark case that $c p_{i, t}$ is $20 \%$ for age $20-69,10 \%$ for age 70-74, and 5\% for age over 75 , respectively. Note that the actual co-payment rate in recent years at the aggregate level was calculated to be around $14 \%$ on average. The co-payment rates for different age groups in the benchmark case have been calculated by taking into account the cohort and age differences in the distribution of the actual population, so that the calculated co-payment rates result in the average co-payment rate at the aggregate level in the benchmark case being the same as the actual average rate (14\%). The total medical expenditure of different age groups calculated in the benchmark case thus becomes very close to the actual amount, while the co-payment rates given in the benchmark case are different from the actual rates in Table 2 . The effect of changes in the co-payment rate for different age groups will be simulated.

Except for a consumption tax, all taxes (a labor income tax, an interest income tax, and an inheritance tax) have been assumed to be fixed at the 2007 rates. The 2007 tax rates were obtained from the SNA data. Note that the consumption tax is the only indirect tax in this paper, and its rate was calculated from the actual total amount of indirect tax revenue in the national account, in order for the consumption tax rate in the benchmark case to result in the close amount of the total indirect tax revenue to the actual one. Thus the consumption tax rate calculated here does not coincide with the actual rate. 


\subsubsection{Technological Progress}

Technological progress of private production plays a very important role. Thus careful attention should be paid to the assumption on technological progress, since the value of technological progress directly affects simulation results. In this paper technological progress is measured by the Solow residual. Following Hayashi and Prescott (2002), the capital share is set at 0.361585 . In the benchmark case the value of technological progress from 2008 is assumed to be $1 \%$.

When values of parameters could be obtained from the existing empirical research, the values have been used in the simulations. The values used in this paper are summarized as follows:

The Values of Parameters

\begin{tabular}{ccccc}
\hline$\delta$ & $\rho$ & $\alpha$ & $\delta_{k}$ & $\beta_{p}$ \\
\hline 0.02 & 2 & 0.63842 & 0.089 & 0.54 \\
\hline
\end{tabular}

\subsection{Benchmark Simulation}

With the assumptions indicated above, the benchmark result is shown in Table 3 , where actual values for 2005 are also presented. Figures 7-1, 7-2, and 7-3 show trends of per capita GDP, the ratio of public pension benefits to GDP, and the ratio of public health insurance benefits to GDP, respectively. All figures show actual and benchmark figures per period. Note that benchmark values for the ratio of public pension benefits to GDP and the ratio of public health insurance benefits to GDP are close to actual values for 2007. The trend of increase in both ratios can be explained by the aging population, as earlier research has indicated (Dekle (2002) and Broda and Weistein (2004)). The benchmark case forecasts that by 2050 , the social security burden ratio will more than double over 2005. Our benchmark case shows that public health insurance benefits would increase by $1 \%$ every 10 years, while 
Tokita et al. (1997) argue that national medical expenditures would increase $40 \%$ in 30 years.

As the last column of Table 3 indicates, the average co-payment rate at the aggregate level is expected to fall because of the growing number of elderly, whose co-payment rate is less than other age groups. Thus, aging of Japan's population increases consumption of public health insurance benefits but reduces aggregate average co-payments.

\subsection{Reform Simulations}

This section simulates the effect of the reform. As presented in the benchmark simulation, an aging population will increase the total amount of public health insurance benefits. To offset increases in benefits, the government has increased the co-payment rate, one of the most prominent changes in the reform. The first simulation investigates its effects.

The second simulation examines the effect of changes in medical costs. The 2006 reform sought to improve efficiency in providing medical services, and it urged medical institutions to provide more preventive care to reduce national medical expenditure. Improvements in efficiency might promote reductions in medical costs or, perversely, might induce increases in costs (Hiroi 1994). The second simulation examines an increase and a decrease in medical costs as effects of the reform.

The final simulation employs a general equilibrium framework to evaluate the argument that government try to peg growth of national medical expenditure to economic growth.

\subsubsection{Increasing the co-payment rate}

The first simulation investigates the effect of increasing the co-payment rate, particularly for the elderly. Results are presented in Tables 4 and 5 . Co-payment rates, $c p_{i, t}$, in the benchmark case are $20 \%$ for the group aged 20-69, $10 \%$ for $70-74$, and $5 \%$ for 75 and older. This first simulation assumed the change in co-payment occurred in 2008 and explored the following four cases. 
In Case (1), only the effect of the change in co-payment for ages 70-74 is simulated.As shown in Table 2, reforms initiated since 2009 have raised the co-payment for ages 70-74 from $10 \%$ to $20 \%$. Case (1) simulates the real reforms, and the increase is evaluated for its effect on economic growth and welfare. In Case (1), the co-payment rate for ages 70-74 increases from $10 \%$ to $20 \%$, but co-payment rates for other age groups remain unchanged as the benchmark case. In Case (2), the co-payment remains $20 \%$ for those aged 20-69, increases from $10 \%$ to $20 \%$ for those aged $70-74$, and increases from $5 \%$ to $20 \%$ for those 75 and older.

Increasing co-payment rates might reduce patients' visits to medical institutions, thereby reducing medical expenditure, $m_{i, t}$, in Case (1) and Case (2). This potential behavioral response is considered in Case (3) and Case $(4)^{21}$. Both cases simulate the effect of a $10 \%$ decrease in $m_{i, t}$, but Case (3) supplements Case (1) and Case (4) supplements Case (2). Comparing Case (3) with Case (1) or Case (4) with Case (2) clarifies the effect of behavioral responses to higher co-payments.

Table 4 shows the results of these four cases. Note that increasing the rate implies that patients' co-payments rise while the cost of public health insurance falls. Panel A in Table 4 shows that reducing the cost of public health insurance reduces social security contribution rates in all cases compared with the benchmark. The reduction in the social security contribution rate is larger when the co-payment for 75 and older rises to the common rate of $20 \%$ in Case (2) compared to Case (1), where the co-payment rate rises to $20 \%$ only for ages 70-74. Due to a reduction in the benefits paid by public health insurance, the national burden ratio and the consumption tax rate decrease, as shown in Panel A of Table 4 .

Increasing the co-payment rate stimulates Japan's economy, although not considerably. Even though, in both Cases (1) and (2) the positive effect on economic growth diminishes over time, Case (2) induces greater growth than Case (1).

\footnotetext{
${ }^{21}$ Analysis of behavioral responses to changes in co-payment has been added to our study at the suggestion of an anonymous reviewer whom we thank.
} 
Table 5 also shows the welfare effect of Cases (1) and (2). Table 5 presents the equivalent variation in Cases (1) and (2), where the minimum expenditure and prices in the benchmark case are bases for comparison. Higher co-payments indicate that patients pay more for medical services at medical institutions, and this is certainly not favorable. However, since people likely consume more medical services as they age, shown as the U-shaped pattern of medical expenditure, higher co-payments encourage people to save in preparation for higher medical expenses when they age. Greater saving increases national income, with positive consequences for all generations, as shown in Table 5. Our simulation model demonstrates that the savings effect dominates the negative effect of higher individual payments. Increasing the co-payment rate expands Japan's GDP and eventually enhances welfare.

Case (1) simulates the definite effect of the 2006 reform, where the co-payment rate for the age group of 70-74 increased to $20 \%$. Table 5 shows that all generations have benefited from raising the co-payment rate. The benefit ranges from 10000 yen for the generation born in 1920 to 3.52 million yen for the generation born in 2000. The benefit is less for older generations because their medical expenditure increase with higher co-payments.

Furthermore, generations born before and in the year 1965 benefit more in Case (1) than (2) because relatively older generations do not pay higher co-payments in Case (1) but will in Case (2). Although Case (1) favors older generations, the stimulus to private saving is relatively larger among younger generations. Therefore, generations born after 1965 are better off in Case (2) because they save more to prepare for higher co-payments when they age. The aggregate effect of encouraging private saving is larger in Case (2) than Case (1); therefore, the long-run effect of a co-payment increase on the macro-economy is greater in Case (2). For example, while the overall effect is 10000 yen in both cases for the generation born in 1920, the generation born in 2000 achieves lifetime benefits equivalent to 7.37 million yen in Case (2). Note that Cases (1) and (2) differ only in co-payment for ages 75 and older: it remains $5 \%$ in Case (1) but increases to $20 \%$ in Case (2). Thus, the overall effect of this increase is 3.85 million yen (7.37 million yen - 3.52 million yen) for the generation born in 
2000. Table 5 shows the effect becomes larger on generations born after 1965 .

Panel B in Table 4 shows the effect of these same increases in co-payment when a behavioral response is considered. If ex-post moral hazard behavior exists, it would produce a decrease in $m_{i, t}$. We assume that the behavioral response to an increase in the co-payment rate is represented by a $10 \%$ decrease in $m_{i, t}$. Cases (3) and (4) in Panel B correspond to Cases (1) and (2) in Panel A, respectively.

As both panels show, the aggregate ex-post moral hazard behavior weakens the effect of reducing the burdens: All of the national burden ratio, the social security contribution rate, and the consumption tax rate do not decrease as much as the case when the aggregate ex-post moral hazard behavior is not taken into account. This can be explained as follows: Due to the ex-post moral hazard behavior, each individual decreases medical expenditure by responding to an increase in the co-payment rate. Thus, they do not need save to prepare for future medical expenditure as much as before when they get aged, and the ex-post moral hazard behavior to result in less savings weakens the stimulative effect of an increase in the co-payment rate on private savings at the aggregate level. Thus, GDP does not expand as much as the case when the aggregate ex-post moral hazard effect does not exist, and a smaller expansion of GDP requires higher burdens on the Japanese economy to fulfill the budget constraint of the government which is given to the economy. Another striking result is the numerical magnitude of the effect of the ex-post moral hazard behavior on the aggregate economy. The magnitude of the effect of ex-post moral hazard behavior on the macroeconomy is striking: $-0.04 \%$ in the short-run in Case (2) $(1.43 \%-1.47 \%$ in 2010$)$. The negative effect persists over time, although effects on the economic growth rate vanish in year 2050 in Table 4. Since the economy once jumps down by the aggregate ex-post moral hazard effect in the short-run and thus it stays along a lower path over time, the aggregate ex-post moral hazard effect exists even in the long-run, while its effect on the growth rate vanishes in around 2050. Since the aggregate ex-post moral hazard effect persists, burdens on the economy - the national burden ratio, the social contribution rate, the consumption tax rate 
— show higher values, even in the long-run, when the behavioral effect is considered. Tables 4 and 5 present in detail the numerical magnitude of the effect of increased co-payment. Table 4 also shows the effect of ex-post moral hazard behavior numerically.

\subsubsection{Efficiency in the Scheme and Provision of Preventive Medical Services}

The second simulation examines the effect of measures to reduce medical expenditure by improving service delivery and preventive care. To address the paradox suggested by Hiroi (1994), the second simulation considers both an increase and a decrease in medical expenditures arising from these two aspects of the reform.

In the second simulation, the U-shaped age pattern of $m_{i, t}$ remains unchanged, although it is assumed to shift by $10 \%$. If public health insurance benefits decrease through efficiencies and/or preventive care, the pattern is assumed to shift downward by $10 \%$. On the other hand, if the public health insurance benefits increase, it is assumed to shift upward by $10 \%$.

Table 6 shows the result of this second simulation. When public health insurance benefits decrease by $10 \%$, the effect resembles that observed when ex-post moral hazard behavior is considered. Economic burdens indicated by the national burden ratio, the social security burden ratio, and the consumption tax rate decrease. However, since private saving is less, national income eventually falls, and short-run GDP growth declines. These negative effects vanish over the long-run, although smaller long-run burdens continue to stay.

The effect is the opposite if efficiencies contribute to increases in public health insurance benefits. Economic burdens increase, and although higher medical expenditures are unwelcome, they promote private saving, boosting economic growth. The positive effect disappears in the long-run, although larger long-run burdens continue to stay.

\subsubsection{Recent Argument}

This final simulation examines the argument that the growth rate of national medical expenditure should not exceed the rate of economic growth. First, the ratio of public health 
insurance benefits to GDP in 2008 as the benchmark case was calculated as $7.846 \%$. Then the amount of 2009 public health insurance benefits was calculated using the benchmark model while assuming that the ratio remained unchanged at $7.846 \%$ after 2008 . The ratios of these calculated values of the public health insurance benefits to the values obtained in the benchmark model were calculated from 2008. The ratio in 2008 is unity, hereafter called "the reduction rate" because it indicates how severely benefits must be reduced if the growth rate of medical expenditure is held to growth in GDP. Using the reduction rate and the age pattern of $m_{i, t}$, we calculated age-specific medical expenditure from 2008. The numerical calculation was repeated. This simulation takes account of individuals' behavioral responses because it used the new value of $m_{i, t}$. This simulation thus examines the case when government announced in 2008 that public health insurance benefits will be reduced in order to try to peg them to GDP.

The result of this simulation appears in Table $7^{22}$. The reduction rate appears in the second column. The reduction rate shows how much the government has to reduce the current public health insurance benefits to implement the current argument. Since government holds the growth rate of medical expenditures constant as a percentage of GDP, the economic burden can be reduced. However, the rising trend in public health insurance benefits can be attributed primarily to the aging population, a circumstance difficult to alter. Thus, to maintain the percentage of GDP as Japan ages, benefit reductions need to become more stringent, and by 2050, government will need to reduce benefits by $45 \%$. Even economic growth under the policy based on the current argument is lower until approximately 2035, although a basis of the current argument is for higher economic growth. A $45 \%$ reduction seems unrealistic, and the expected dampening of economic growth likewise suggests the current argument is unreasonable.

\footnotetext{
${ }^{22}$ As shown in Table 7 , the ratio of the national medical expenditure to GDP does not coincide with $7.846 \%$ from 2009, since GDP in this simulation differ from the benchmark model.
} 


\section{Concluding Remarks}

The paper has investigated the effect of public health insurance reforms on Japan's economic growth and welfare, by simulating the reform for an aging Japan, in a dynamic computable general equilibrium framework.

The paper has used actual and projected population data to capture realistic demographics, and the effects of the reform as well as recent policy arguments have been evaluated in a dynamic context. Our results are summarized as follows.

First, increasing the co-payment rate, one of the most prominent changes in the reform, would improve economic growth and welfare by encouraging private saving. However, the magnitude of the effect on economic growth is not large - $0.0 \%$ and $0.01 \%$ in year 2050 depending on the change in the co-payment rate, and $0.01 \%$ to $0.09 \%$ in the short-run. The positive effect on economic growth is relatively larger when the policy change is implemented, but the magnitude of the positive effect decreases over time. On the other hand, the positive effect of increasing the co-payment rate on lifetime income or welfare is greater among relatively younger generations. Our simulation model estimates that the increase in copayment rate in the reform have induced benefits which vary between 10000 yen for the generation born in 1920 and 3.52 million yen for the generation born in 2000 .

Second, potential ex-post moral hazard behavior also results in a decrease in medical expenditures, although it weakens the benefits to economic growth of increasing co-payment rates. The maximum short-run effect of the ex-post moral hazard on economic growth is measured at $-0.04 \%$ when medical expenditures decrease by $10 \%$ because of the behavior.

Third, the rise in future public health insurance benefits can mainly be explained by Japan's aging population, and increasing the co-payment rate does little to reduce future public health insurance benefits, even when re-examined in a general equilibrium framework.

Fourth, reducing medical costs through efficiencies, preventive care, or technological progress has little effect on future economic burdens. A change in the national burden ratio in 2050 is merely $1.2 \%$ points even if per capita medical costs change by $10 \%$. 
Finally, if government tries to hold public health insurance benefits as a percentage of GDP, it must continually reduce benefits, perhaps up to $45 \%$ by 2050 . Such a policy also restrains economic growth until approximately 2035.

Our simulation results indicate that the reform discussed in this paper is not particularly effective in reducing future national medical expenditure, and greater efficiencies and emphasis on preventive care do not significantly influence the macro-economy even if they reduce medical expenditures. Their miniscule macroeconomic effect suggests that future questions about the efficiency of the Japanese public health insurance and/or national medical expenditure should be examined in a microeconomic rather than macroeconomic context.

\section{References}

[1] Auerbach, A. and L. J. Kotlikoff (1983) " An examination of empirical test of social security and savings," in E. Helpman, A. Razin and E. Sadka eds., Social Policy Evaluation: An Economic Perspective, 161-179.

[2] Broda, C. and D. E. Weinstein (2004) "Happy news from the dismal science: Reassessing Japanese fiscal policy and sustainability," NBER Working Paper 10988.

[3] Dekle, R. (2002) "Population aging in Japan: its impact on future saving, investment, and budget deficits," Department of Economics, USC

[4] Friedman, B. M., and M. Warshawsky (1988) "Annuity prices and saving behavior in the United States," in Z. Bodie, J. Shoven, and D. Wise eds., Pensions in the U.S. Economy, 53-77, University of Chicago Press

[5] Friedman, B. M., and M. Warshawsky (1990) "The cost of annuities: implications for saving behavior and bequests," Quarterly Journal of Economics 105(1), 135-154.

[6] Hayashi, F. (1995) "Is the Japanese extended family altruistically linked? A test based on Engel curves," Journal of Political Economy 103(2), 661-674. 
[7] Hayashi, F. and E. C. Prescott (2002) "The 1990s in Japan: A Lost Decade," Review of Economic Dynamics 5(1), 206-235.

[8] Hiroi, Y. (1994) "An increase in the medical cost and economic growth: An access, technological progress, and population aging (in Japanese)," Japanese Journal of Health Economics and Policy 1, 69-82.

[9] Horioka, C. Y. and W. Watanabe (1997) "Why do people save? A micro-analysis of motives for household saving in Japan," Economic Journal 107(442), 537-552.

[10] Ii, M. and S. Bessho (2006) "A survey: The empirical literature on health economics of Japan and health policies (in Japanese)," Financial Review 80(1), 117-156.

[11] Iwamoto, Y., R. R. Kato, and M. Hidaka (1993) "Public pension and an aging population," Review of Social Policy 2, 1-12.

[12] Johansson, P.-O. (2000) "Properties of actuarially fair and pay-as-you-go health insurance schemes for the elderly. An OLG model approach," Journal of Health Economics 19, $477-498$.

[13] Kato, R. R. (2002) "Government deficit, public investment, and public capital in the transition to an aging Japan," Journal of the Japanese and International Economies 16, $462-491$.

[14] Reinhardt, U. E. (2000) "Health care for the aging baby boom: Lessons from abroad," Journal of Economic Perspectives 14(2), 71-83.

[15] Tokita, T. (2002) "The prospects for reform of the Japanese Healthcare system," Pharmacoeconomics 20(S3), 55-66.

[16] Tokita, T., Chino, T., Kitaki, H., Yamamoto, I., Miyagi, M. (1997) "The present and future National Medical Expenditure in Japan (in Japanese)," Keizai Bunseki 152. 
[17] Zweifel, P. and F. Breyer (1997) Health Economics. New York, Oxford University Press. 
Figure 1

The Structure of the Public Health Insurance of Japan

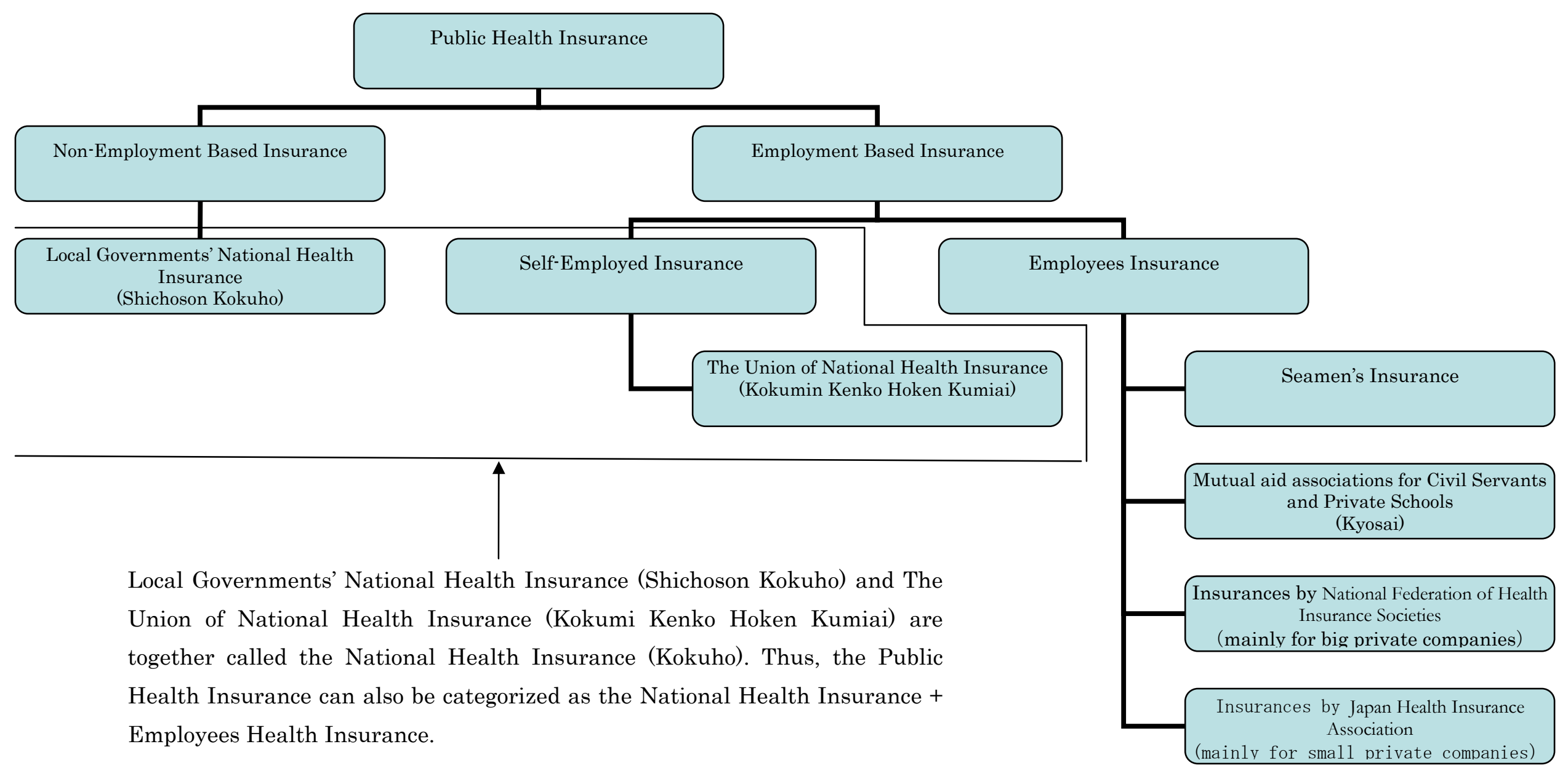


Table 1

\begin{tabular}{|c|c|c|}
\hline & Type & Insurers \\
\hline National Health Insurance & $\begin{array}{l}\text { Local Governments National Health Insurance } \\
\text { (Shichoson Kokuho) } \\
\text { Unions of National Health Insurance } \\
\text { (Kokumin Kenko Hoken Kumiai) }\end{array}$ & $\begin{array}{l}\text { Local governments } \\
\text { Each union of National Health } \\
\text { Insurances }\end{array}$ \\
\hline Employees Health Insurance & $\begin{array}{c}\text { Seamen's Insurance } \\
\text { Insurances by mutual aid associations } \\
\text { Insurances by each member of National Federation of } \\
\text { Health Insurance Societies } \\
\text { Insurance by Japan Health Insurance Association }\end{array}$ & $\begin{array}{c}\text { Central Government } \\
\text { Each mutual aid association } \\
\text { Each member of National Federation } \\
\text { of Health Insurance Societies } \\
\text { Japan Health Insurance Association }\end{array}$ \\
\hline
\end{tabular}


Figure 2

(New Public Health Insurance for the Elderly)

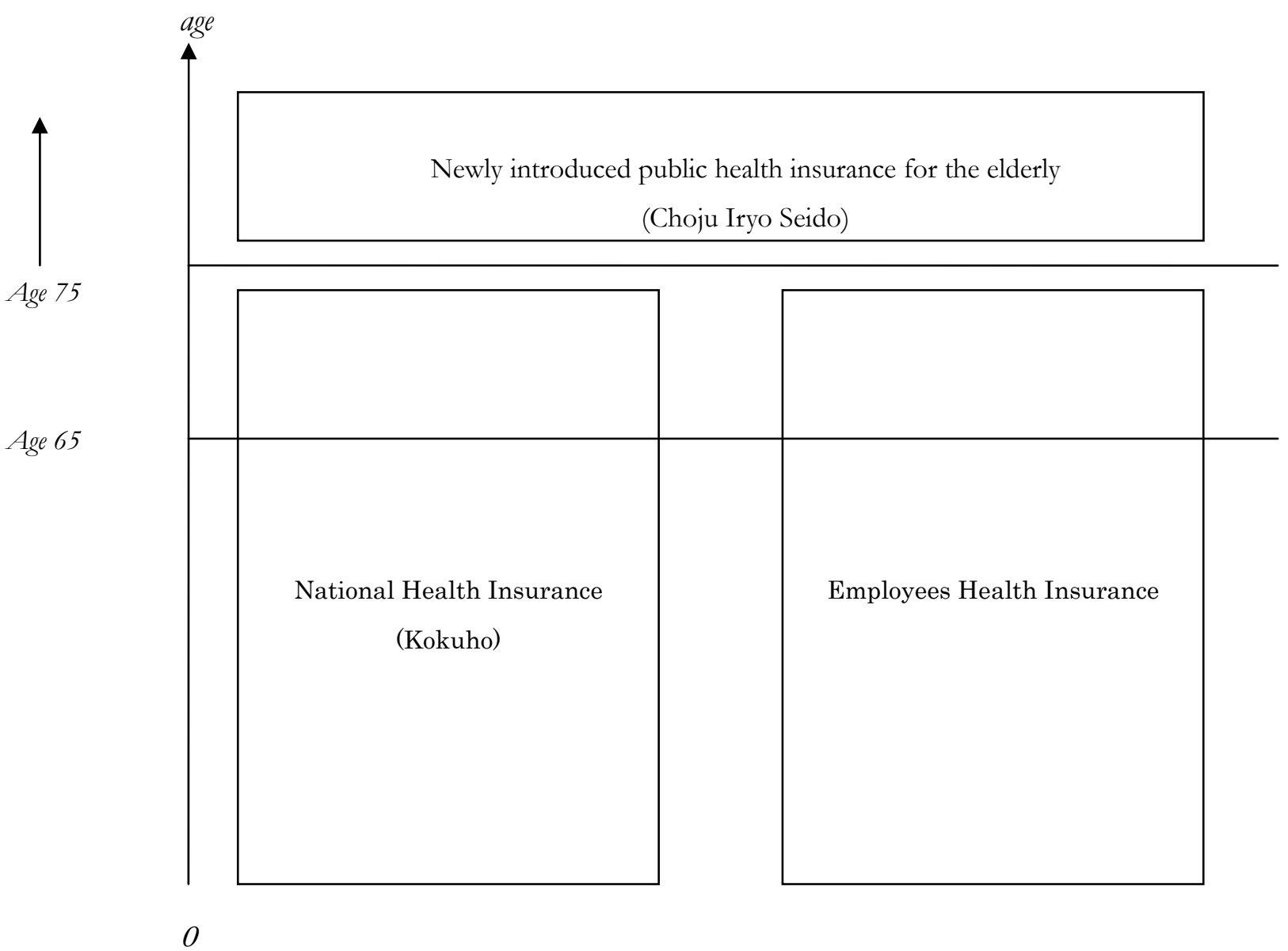


Figure 3

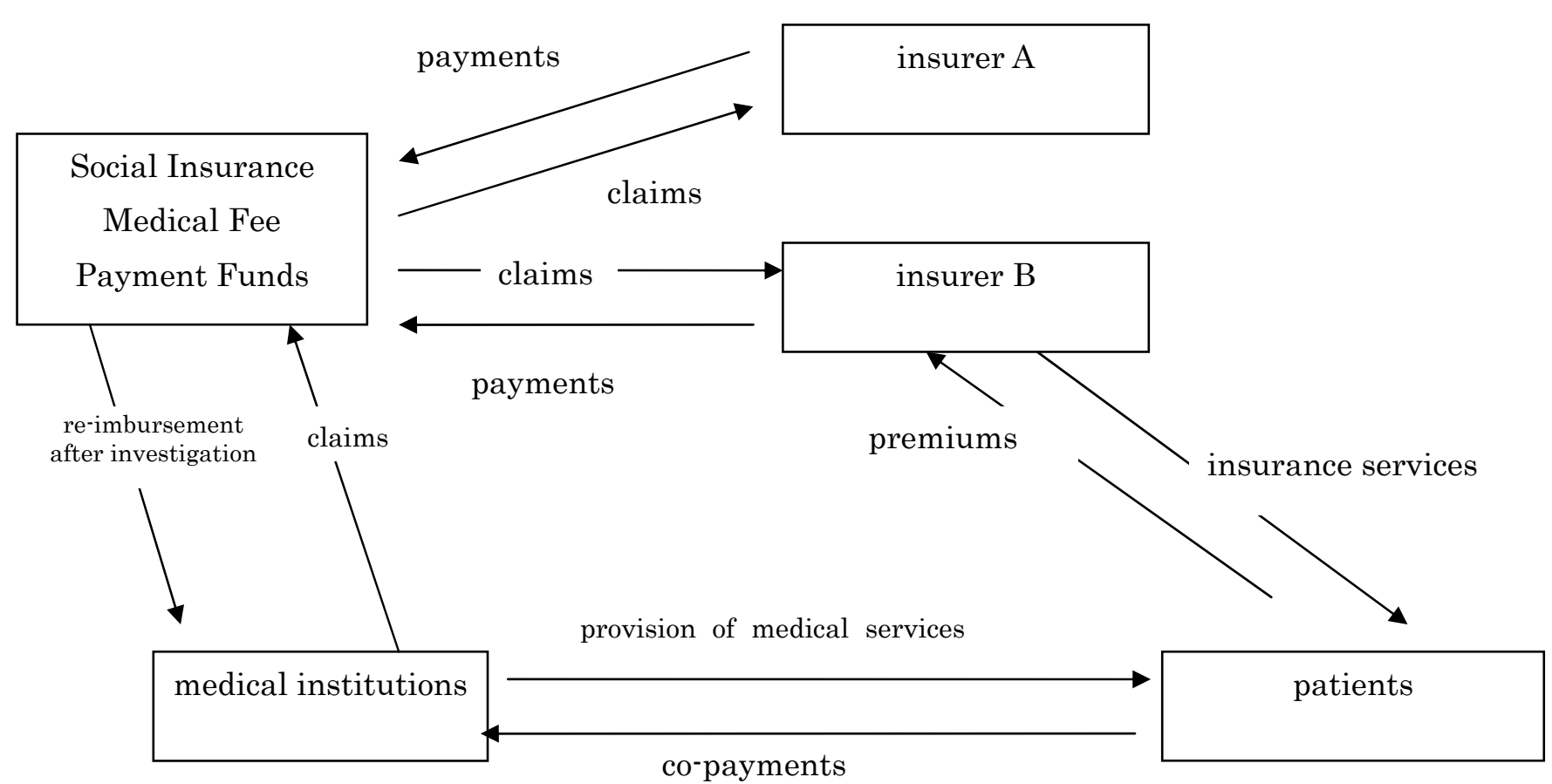


Figure 4

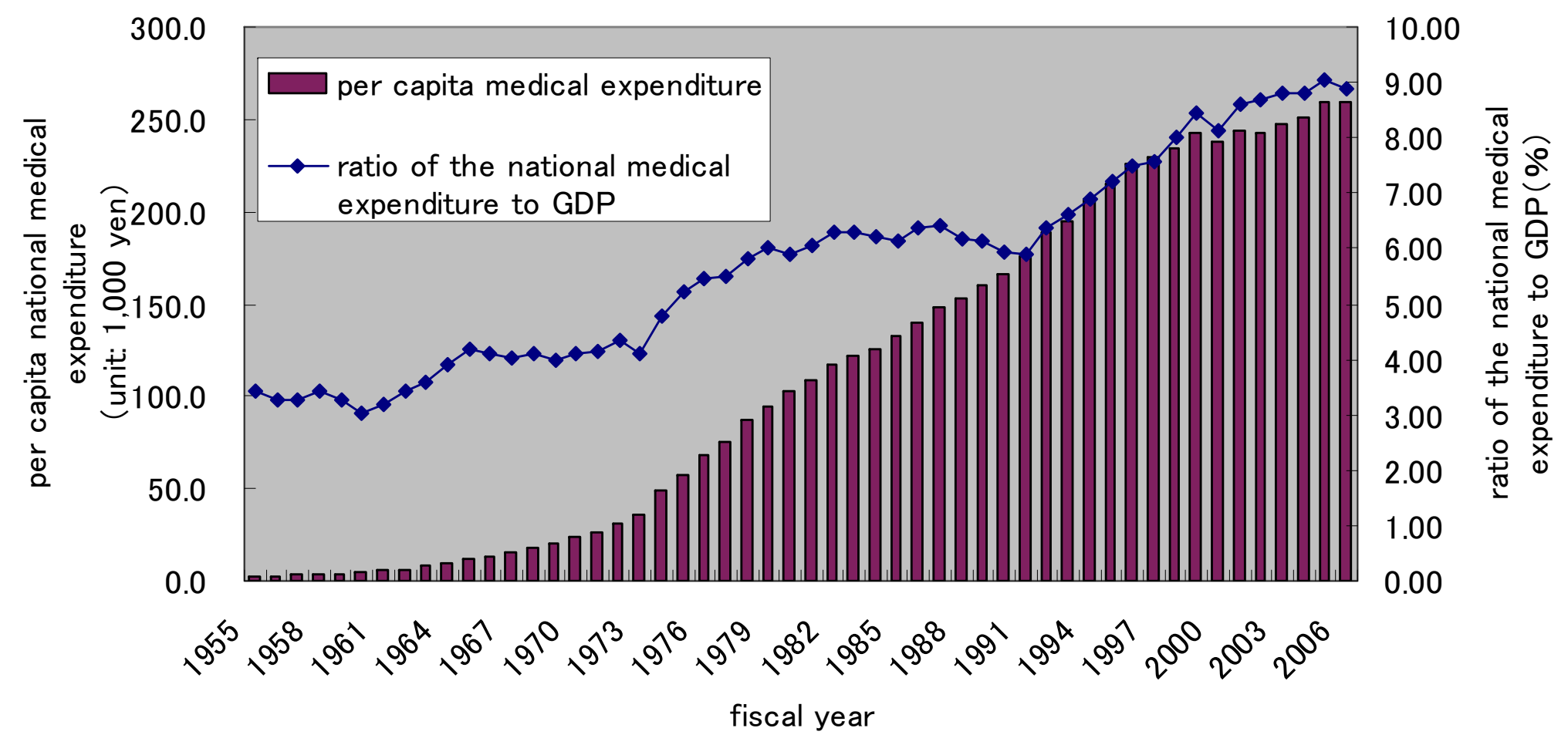

Data Source: Ministry of Health, Labor and Welfare 
Figure 5: Aging Rates

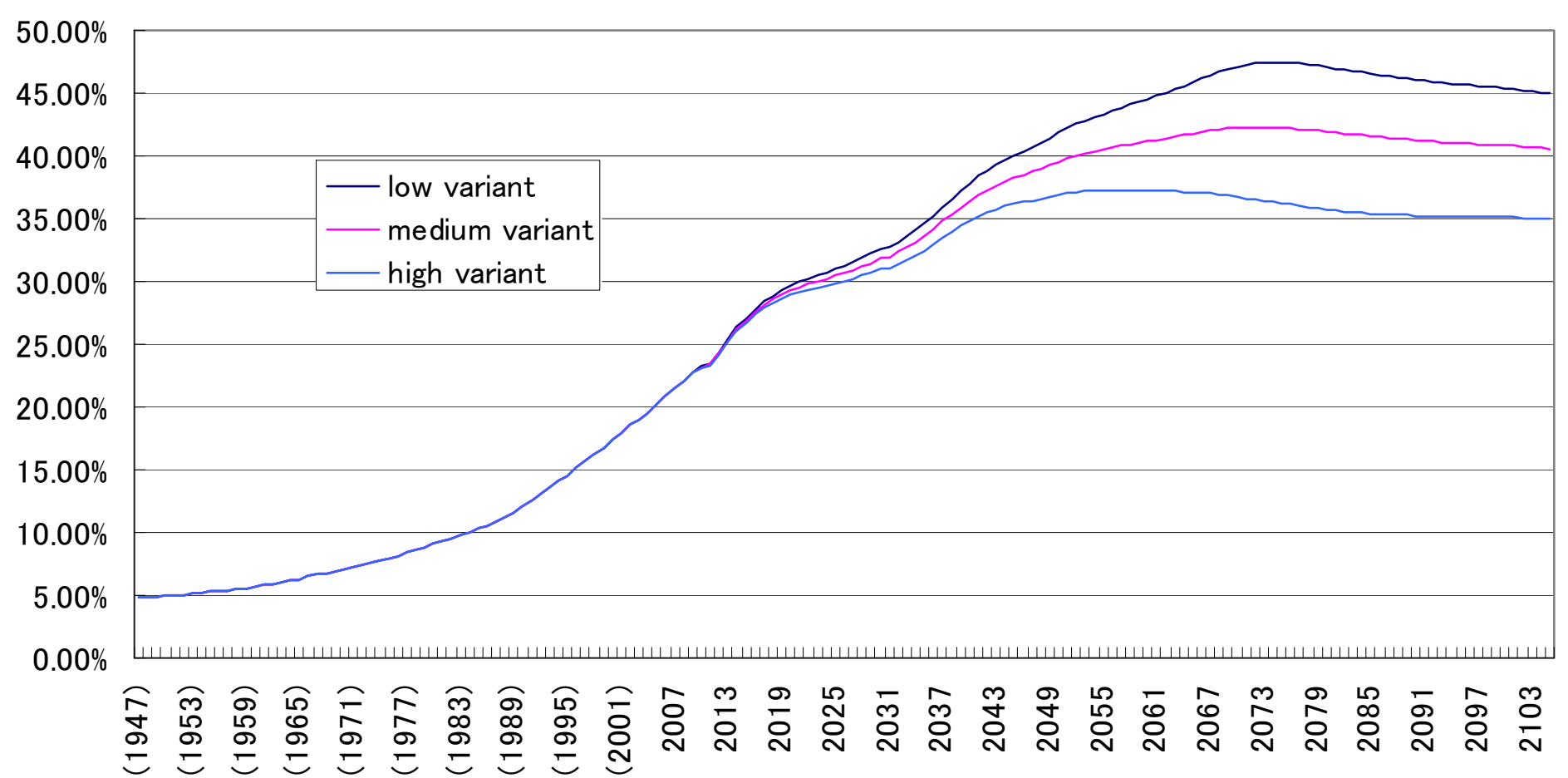

Until 2005 actual data has been used. From 2006 the latest population projection by the National Institute of Population and Social Security Research has been used. 
Figure 6

(The age group difference in the national medical expenditure of year 2006)

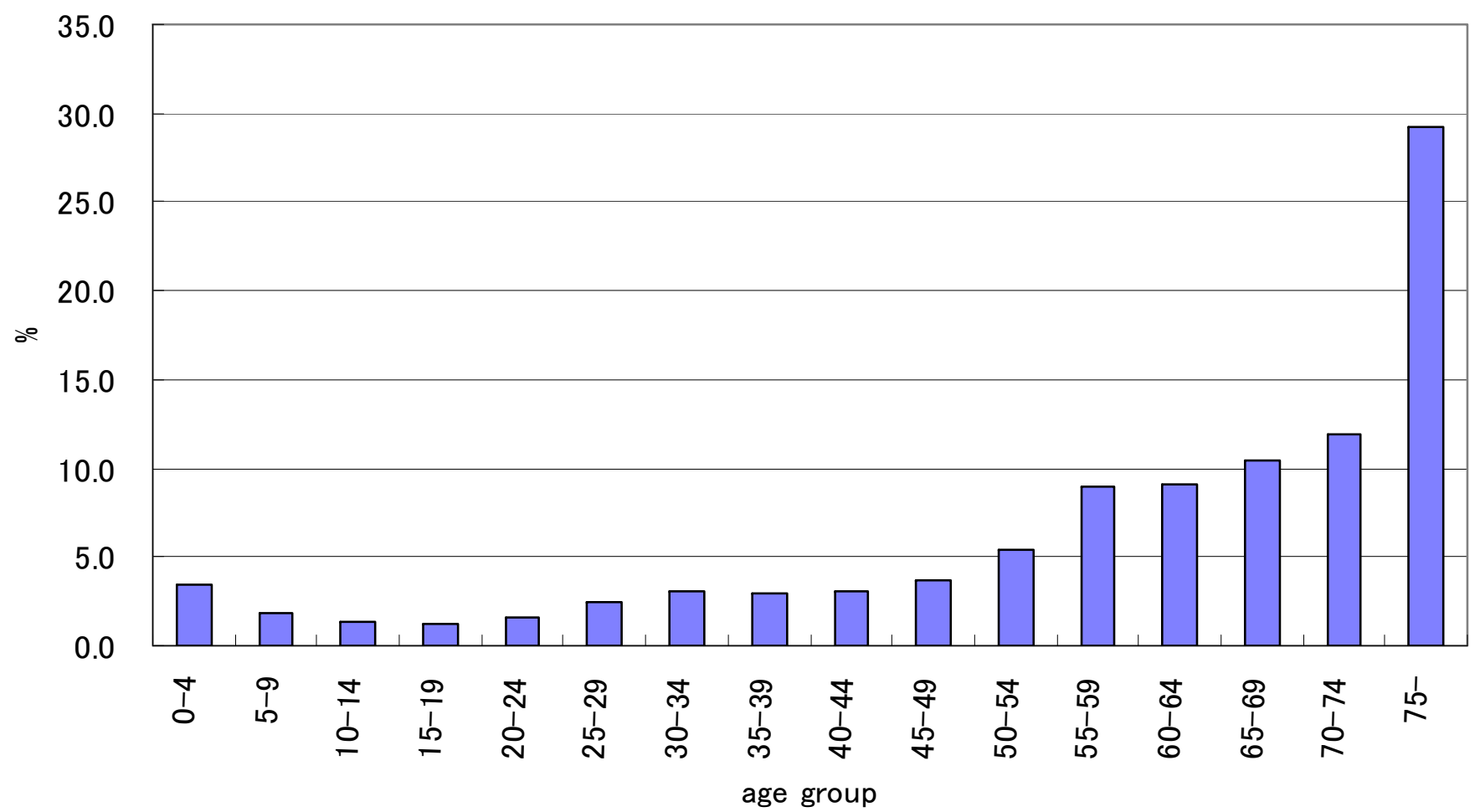

Data Source: Ministry of Health, Labor and Welfare 
Table 2: The Co-Payment Rates

\begin{tabular}{c|c|c|c|c} 
Age & $\begin{array}{c}0 \sim \text { before junior high } \\
\text { school }\end{array}$ & After junior high school $\sim 69$ & $\begin{array}{c}70 \sim \\
74\end{array}$ & $\begin{array}{c}75 \text { and } \\
\text { over }\end{array}$ \\
\hline $\begin{array}{c}\text { Co-payment } \\
\text { rates }\end{array}$ & $20 \%$ & $30 \%$ & $20 \% *$ & $10 \%$
\end{tabular}

*) $\quad 10 \%$ until the end of March of 2009

Notice: a $30 \%$ rate is applied to the elderly of 70 and over with high income. 
Table 3. Benchmark simulation results

\begin{tabular}{|c|c|c|c|c|c|c|c|c|c|}
\hline Year & $\begin{array}{c}\text { Outstanding } \\
\text { debts }\end{array}$ & $\begin{array}{c}\text { GDP } \\
\text { Growth rate } \\
\%\end{array}$ & $\begin{array}{c}\text { Primary } \\
\text { balance } \\
\text { GDP ratio }\end{array}$ & $\begin{array}{c}\text { National } \\
\text { burden } \\
\text { GDP ratio }\end{array}$ & $\begin{array}{c}\text { Contribution } \\
\text { rate } \\
\%\end{array}$ & $\begin{array}{c}\text { Public } \\
\text { pension } \\
\text { benefits } \\
\text { GDP ratio }\end{array}$ & $\begin{array}{l}\text { Public health } \\
\text { insurance } \\
\text { benefits } \\
\text { GDP ratio }\end{array}$ & $\begin{array}{c}\text { Interest } \\
\text { rate } \\
\\
\%\end{array}$ & $\begin{array}{c}\text { Co-payment } \\
\text { rate } \\
\% \\
\%\end{array}$ \\
\hline $\begin{array}{l}\text { Actual } \\
2005 \\
\end{array}$ & 1.279 & 2.5262 & -7.445 & 27.047 & 19.552 & 8.437 & 6.421 & & 14.4 \\
\hline $\begin{array}{l}\text { Simulat } \\
2005\end{array}$ & 1.279 & 1.745 & 3.781 & 38.032 & 15.185 & 8.586 & 6.462 & 8.259 & 13.5 \\
\hline 2010 & 1.359 & 1.381 & 4.054 & 39.005 & 15.256 & 10.024 & 7.292 & 8.167 & 13.0 \\
\hline 2015 & 1.489 & 0.795 & 6.822 & 44.927 & 18.860 & 12.162 & 8.112 & 7.561 & 12.4 \\
\hline 2020 & 1.507 & 0.903 & 8.955 & 48.967 & 20.946 & 13.395 & 8.878 & 7.381 & 11.7 \\
\hline 2025 & 1.507 & 0.777 & 9.177 & 50.344 & 22.204 & 13.932 & 9.556 & 7.331 & 11.1 \\
\hline 2030 & 1.507 & 0.456 & 9.022 & 51.668 & 23.873 & 14.694 & 10.232 & 7.173 & 10.9 \\
\hline 2035 & 1.507 & 0.159 & 8.932 & 53.510 & 26.037 & 15.893 & 10.939 & 6.957 & 10.8 \\
\hline 2040 & 1.507 & -0.028 & 9.170 & 56.334 & 28.889 & 17.876 & 11.607 & 6.787 & 10.8 \\
\hline 2045 & 1.507 & 0.079 & 9.808 & 58.641 & 30.669 & 19.082 & 12.246 & 6.970 & 10.5 \\
\hline 2050 & 1.507 & 0.124 & 10.506 & 60.477 & 31.851 & 19.745 & 12.915 & 7.305 & 10.1 \\
\hline
\end{tabular}

Note: Public health insurance benefits exclude the amount of co-payments. 
(year $1990=1) \quad$ Figure $7-1:$ Per Capita GDP (Benchmark Model)

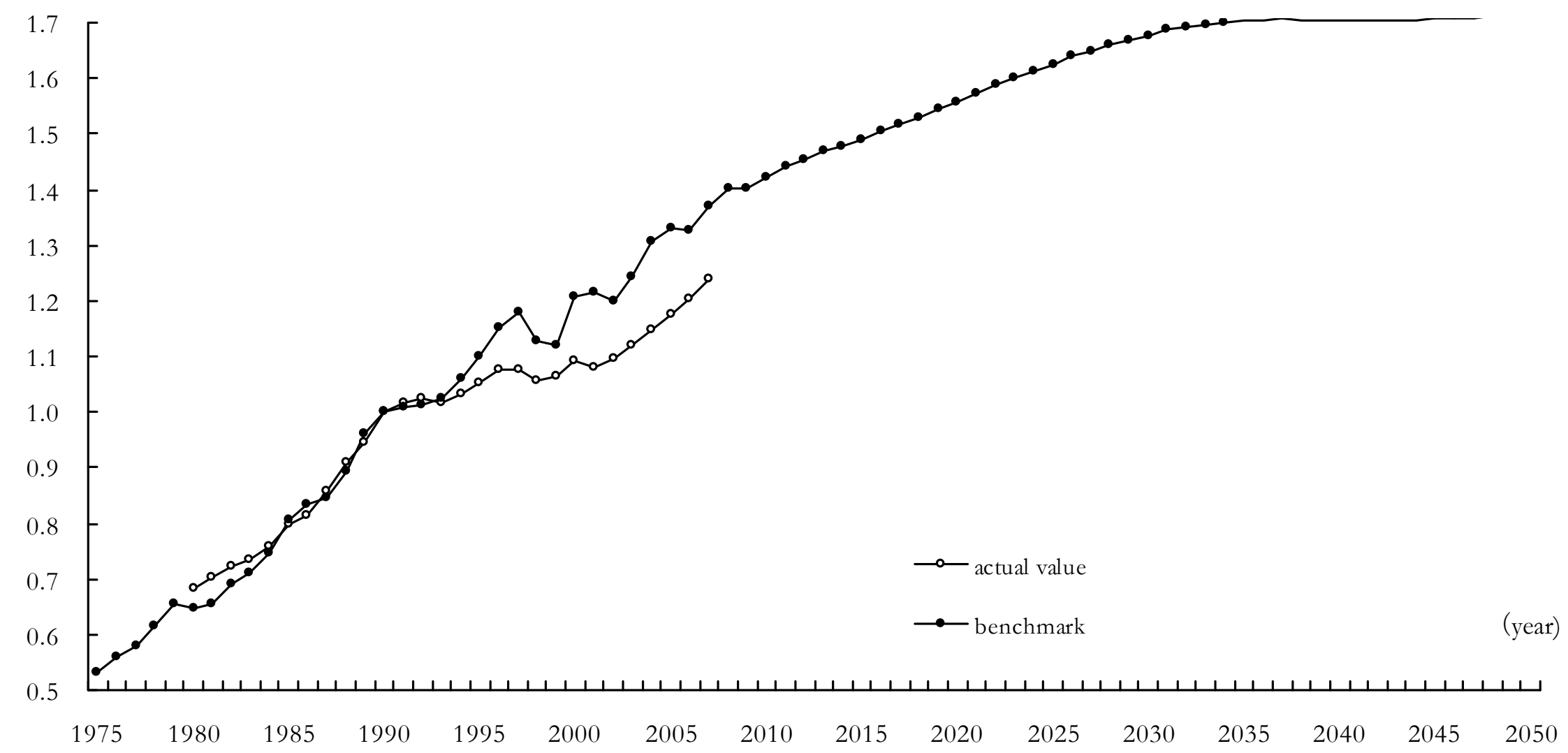


(\%) Figure 7-2: The Ratio of Public Pension Benefits to GDP (Benchmark Model)

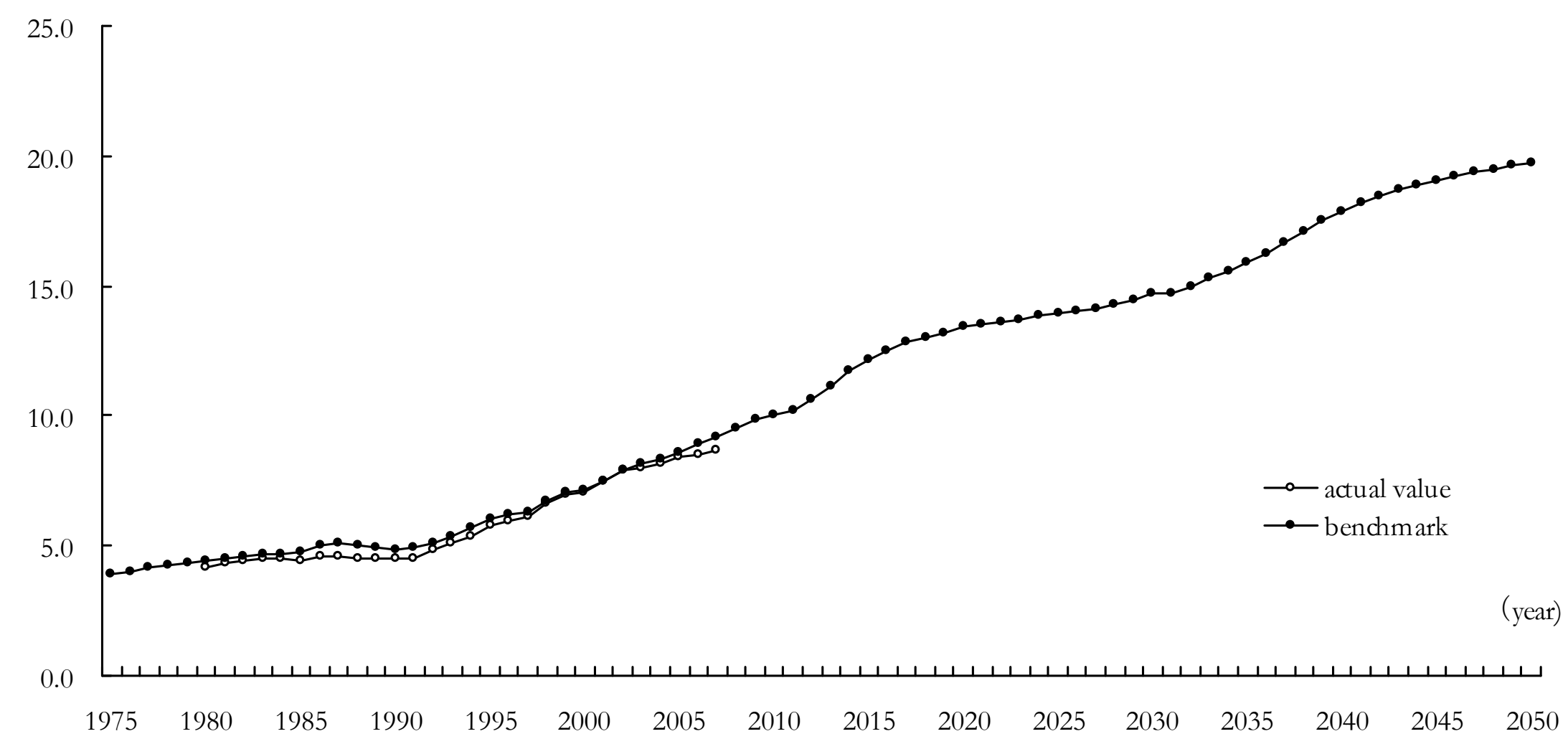


(\%) Figure 7-3 : The Ratio of Public Health Insurance Benefits to GDP (Benchmark Model)

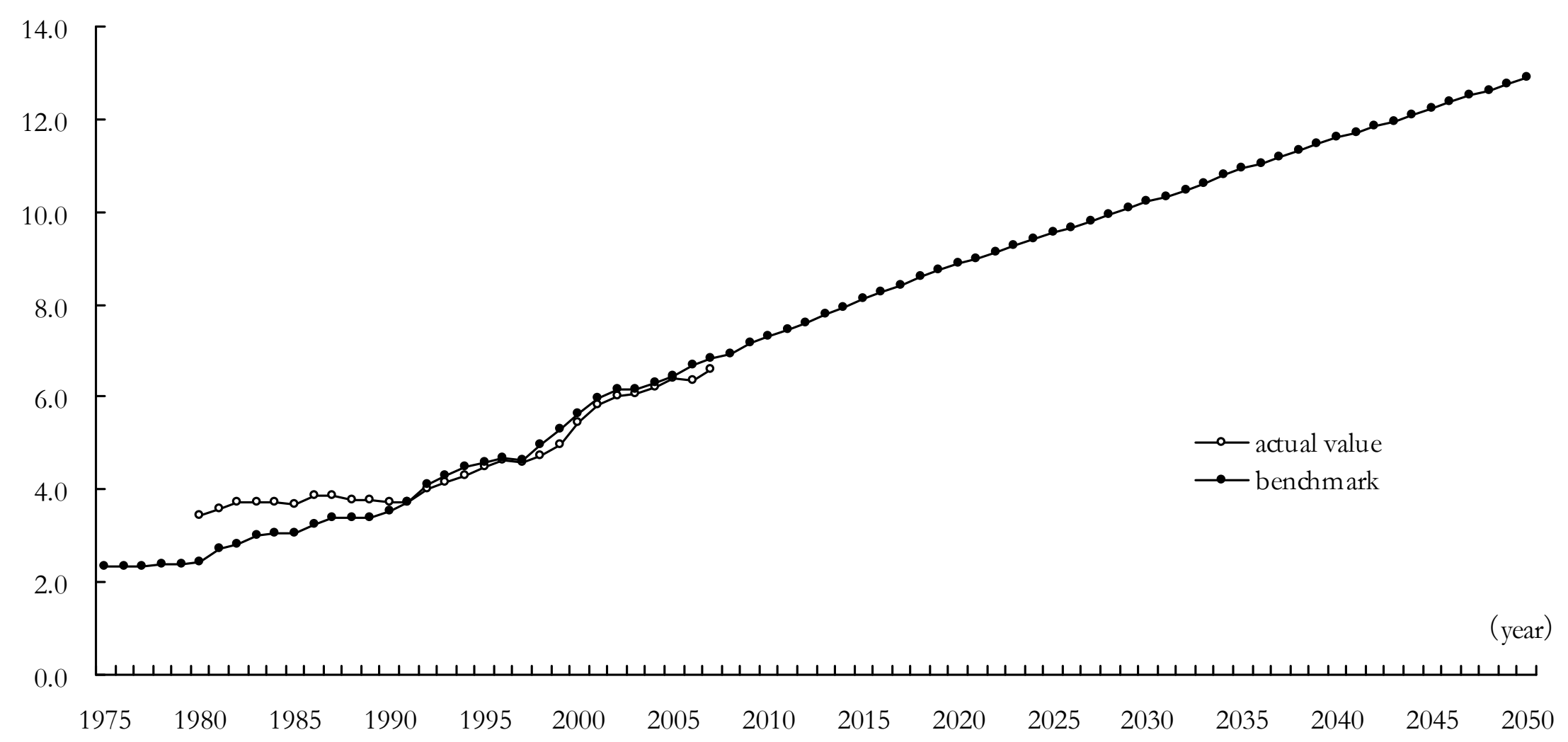


Table 4. Increases in the co-payment rate

Panel A: No behavioral response in medical consultation:

\begin{tabular}{|c|c|c|c|c|c|c|c|c|c|c|c|c|}
\hline & \multicolumn{3}{|c|}{ National burden ratio } & \multicolumn{3}{|c|}{ Social security contribution rate } & \multicolumn{3}{|c|}{ Consumption tax rate } & \multicolumn{3}{|c|}{ GDP growth rate } \\
\hline & Benchmark & Case (1) & Case (2) & Benchmark & Case (1) & Case (2) & Benchmark & Case (1) & Case (2) & Benchmark & Case (1) & Case (2) \\
\hline 2010 & 39.01 & 38.89 & 38.25 & 15.26 & 15.14 & 14.67 & 35.76 & 35.71 & 35.47 & 1.38 & 1.39 & 1.47 \\
\hline 2015 & 44.93 & 44.79 & 43.95 & 18.86 & 18.73 & 18.16 & 41.68 & 41.62 & 41.19 & 0.80 & 0.80 & 0.85 \\
\hline 2020 & 48.97 & 48.80 & 47.79 & 20.95 & 20.78 & 20.09 & 46.38 & 46.30 & 45.74 & 0.90 & 0.91 & 0.94 \\
\hline 2025 & 50.34 & 50.19 & 49.01 & 22.20 & 22.07 & 21.22 & 47.23 & 47.15 & 46.46 & 0.78 & 0.78 & 0.80 \\
\hline 2030 & 51.67 & 51.52 & 50.22 & 23.87 & 23.75 & 22.79 & 47.41 & 47.33 & 46.57 & 0.46 & 0.46 & 0.47 \\
\hline 2035 & 53.51 & 53.34 & 51.97 & 26.04 & 25.90 & 24.86 & 47.84 & 47.75 & 46.94 & 0.16 & 0.16 & 0.17 \\
\hline 2040 & 56.33 & 56.14 & 54.70 & 28.89 & 28.72 & 27.62 & 49.07 & 48.97 & 48.13 & -0.03 & -0.03 & -0.02 \\
\hline 2045 & 58.64 & 58.42 & 56.87 & 30.67 & 30.46 & 29.28 & 50.66 & 50.54 & 49.64 & 0.08 & 0.08 & 0.09 \\
\hline 2050 & 60.48 & 60.27 & 58.56 & 31.85 & 31.66 & 30.33 & 51.99 & 51.88 & 50.89 & 0.12 & 0.12 & 0.13 \\
\hline
\end{tabular}

Co-payment rates

Benchmark: $\quad 20 \%$ for the age group of $20-69,10 \%$ for $70-74$, and $5 \%$ for 75 and over Case (1): $\quad 20 \%$ for the age group of $20-69,20 \%$ for $70-74$, and $5 \%$ for 75 and over Case (2): $\quad 20 \%$ for all age groups 
Panel B: Behavioral response in medical consultation:

\begin{tabular}{|c|c|c|c|c|c|c|c|c|c|c|c|c|}
\hline & \multicolumn{3}{|c|}{ National burden ratio } & \multicolumn{3}{|c|}{ Social security contribution rate } & \multicolumn{3}{|c|}{ Consumption tax rate } & \multicolumn{3}{|c|}{ GDP growth rate } \\
\hline & Benchmark & Case (3) & Case (4) & Benchmark & Case (3) & Case (4) & Benchmark & Case (3) & Case (4) & Benchmark & Case (3) & Case (4) \\
\hline 2010 & 39.01 & 38.82 & 37.98 & 15.26 & 15.05 & 14.24 & 35.76 & 35.67 & 35.29 & 1.38 & 1.38 & 1.43 \\
\hline 2015 & 44.93 & 44.70 & 43.67 & 18.86 & 18.62 & 17.65 & 41.68 & 41.57 & 41.05 & 0.80 & 0.80 & 0.82 \\
\hline 2020 & 48.97 & 48.68 & 47.45 & 20.95 & 20.65 & 19.50 & 46.38 & 46.25 & 45.61 & 0.90 & 0.91 & 0.92 \\
\hline 2025 & 50.34 & 50.09 & 48.62 & 22.20 & 21.95 & 20.57 & 47.23 & 47.09 & 46.33 & 0.78 & 0.78 & 0.79 \\
\hline 2030 & 51.67 & 51.44 & 49.80 & 23.87 & 23.64 & 22.10 & 47.41 & 47.29 & 46.42 & 0.46 & 0.46 & 0.47 \\
\hline 2035 & 53.51 & 53.26 & 51.51 & 26.04 & 25.78 & 24.13 & 47.84 & 47.71 & 46.79 & 0.16 & 0.16 & 0.17 \\
\hline 2040 & 56.33 & 56.04 & 54.21 & 28.89 & 28.58 & 26.83 & 49.07 & 48.93 & 47.96 & -0.03 & -0.03 & -0.02 \\
\hline 2045 & 58.64 & 58.28 & 56.32 & 30.67 & 30.30 & 28.42 & 50.66 & 50.49 & 49.46 & 0.08 & 0.08 & 0.08 \\
\hline 2050 & 60.48 & 60.13 & 57.95 & 31.85 & 31.51 & 29.41 & 51.99 & 51.82 & 50.69 & 0.12 & 0.13 & 0.13 \\
\hline
\end{tabular}

\section{Co-payment rates}

Benchmark: $\quad 20 \%$ for the age group of $20-69,10 \%$ for $70-74$, and $5 \%$ for 75 and over Case (3): $\quad 20 \%$ for the age group of $20-69,20 \%$ for $70-74$, and $5 \%$ for 75 and over Case (4): $\quad 20 \%$ for all age groups 
Table 5. Welfare effects of an increase in the co-payment rate

\begin{tabular}{|c|c|c|}
\hline & Case (1) & Case (2) \\
\hline 1920 & 0.01 & 0.01 \\
\hline 1925 & 0.02 & 0.01 \\
\hline 1930 & 0.03 & 0.01 \\
\hline 1935 & 0.05 & 0.02 \\
\hline 1940 & 0.06 & 0.02 \\
\hline 1945 & 0.09 & 0.02 \\
\hline 1950 & 0.12 & 0.04 \\
\hline 1955 & 0.17 & 0.08 \\
\hline 1960 & 0.26 & 0.18 \\
\hline 1965 & 0.41 & 0.41 \\
\hline 1970 & 0.76 & 0.94 \\
\hline 1975 & 1.16 & 1.68 \\
\hline 1980 & 1.79 & 2.83 \\
\hline 1985 & 1.94 & 3.72 \\
\hline 1990 & 3.61 & 6.26 \\
\hline 1995 & 3.31 & 6.60 \\
\hline 2000 & 3.52 & 7.37 \\
\hline
\end{tabular}

Unit: million yen in the FY2000 price

The above values are measured in the equivalent variation (EV), where the minimum expenditure and the prices in the benchmark case have been used as the bases for comparison. The numbers in the first column indicate the years when they were born, and thus they imply generations.

The co-payment rates

Benchmark: $20 \%$ for the age group of $20-69,10 \%$ for $70-74$, and $5 \%$ for 75 and over Case (1): $\quad 20 \%$ for the age group of $20-69,20 \%$ for $70-74$, and $5 \%$ for 75 and over Case (2): $\quad 20 \%$ for all age groups 
Table 6. Changes in medical expenditures (unit: \%)

\begin{tabular}{|c|c|c|c|c|c|c|c|c|c|c|c|c|}
\hline & \multicolumn{3}{|c|}{ National burden ratio } & \multicolumn{3}{|c|}{ Social security contribution rate } & \multicolumn{3}{|c|}{ Consumption tax rate } & \multicolumn{3}{|c|}{ GDP growth rate } \\
\hline & benchmark & $\begin{array}{c}10 \% \\
\text { increase }\end{array}$ & $\begin{array}{c}10 \% \\
\text { decrease }\end{array}$ & benchmark & $\begin{array}{c}10 \% \\
\text { increase }\end{array}$ & $\begin{array}{c}10 \% \\
\text { decrease }\end{array}$ & benchmark & $\begin{array}{c}10 \% \\
\text { increase }\end{array}$ & $\begin{array}{c}10 \% \\
\text { decrease }\end{array}$ & benchmark & $\begin{array}{c}10 \% \\
\text { increase }\end{array}$ & $\begin{array}{c}10 \% \\
\text { decrease }\end{array}$ \\
\hline 2010 & 39.01 & 39.68 & 38.32 & 15.26 & 16.10 & 14.42 & 35.76 & 36.13 & 35.39 & 1.38 & 1.41 & 1.35 \\
\hline 2015 & 44.93 & 45.65 & 44.20 & 18.86 & 19.79 & 17.93 & 41.68 & 42.03 & 41.33 & 0.80 & 0.81 & 0.78 \\
\hline 2020 & 48.97 & 49.75 & 48.17 & 20.95 & 21.96 & 19.93 & 46.38 & 46.75 & 46.01 & 0.90 & 0.91 & 0.90 \\
\hline 2025 & 50.34 & 51.19 & 49.49 & 22.20 & 23.29 & 21.11 & 47.23 & 47.61 & 46.84 & 0.78 & 0.78 & 0.77 \\
\hline 2030 & 51.67 & 52.57 & 50.75 & 23.87 & 25.03 & 22.71 & 47.41 & 47.82 & 47.00 & 0.46 & 0.46 & 0.45 \\
\hline 2035 & 53.51 & 54.49 & 52.52 & 26.04 & 27.27 & 24.80 & 47.84 & 48.27 & 47.41 & 0.16 & 0.16 & 0.16 \\
\hline 2040 & 56.33 & 57.37 & 55.28 & 28.89 & 30.19 & 27.58 & 49.07 & 49.53 & 48.61 & -0.03 & -0.03 & -0.03 \\
\hline 2045 & 58.64 & 59.74 & 57.52 & 30.67 & 32.04 & 29.29 & 50.66 & 51.13 & 50.17 & 0.08 & 0.08 & 0.08 \\
\hline 2050 & 60.48 & 61.65 & 59.29 & 31.85 & 33.30 & 30.40 & 51.99 & 52.48 & 51.49 & 0.12 & 0.12 & 0.13 \\
\hline
\end{tabular}

Table 7: The Effect of the Constant Ratio of National Medical Expenditure to GDP (unit: \%)

\begin{tabular}{|c|c|c|c|c|c|c|c|c|c|c|c|}
\hline & \multirow[t]{2}{*}{$\begin{array}{l}\text { Reduction } \\
\text { Rate }\end{array}$} & \multicolumn{2}{|c|}{$\begin{array}{c}\text { National Medical } \\
\text { Expenditure ratio to } \\
\text { GDP }\end{array}$} & \multicolumn{2}{|c|}{ National burden ratio } & \multicolumn{2}{|c|}{$\begin{array}{l}\text { Social security } \\
\text { contribution rate }\end{array}$} & \multicolumn{2}{|c|}{ Consumption tax rate } & \multicolumn{2}{|c|}{ GDP growth rate } \\
\hline & & benchmark & constant & benchmark & constant & benchmark & constant & benchmark & constant & benchmark & constant \\
\hline 2010 & 4.0 & 7.29 & 7.02 & 39.01 & 39.06 & 15.26 & 14.71 & 35.76 & 35.60 & 1.38 & 1.17 \\
\hline 2015 & 16.0 & 8.11 & 7.10 & 44.93 & 44.45 & 18.86 & 17.41 & 41.68 & 41.50 & 0.80 & 0.67 \\
\hline 2020 & 21.0 & 8.88 & 7.16 & 48.97 & 47.87 & 20.95 & 18.66 & 46.38 & 46.02 & 0.90 & 0.83 \\
\hline 2025 & 26.0 & 9.56 & 7.19 & 50.34 & 48.65 & 22.20 & 19.17 & 47.23 & 46.67 & 0.78 & 0.73 \\
\hline 2030 & 31.0 & 10.23 & 7.20 & 51.67 & 49.33 & 23.87 & 20.08 & 47.41 & 46.62 & 0.46 & 0.43 \\
\hline 2035 & 36.0 & 10.94 & 7.20 & 53.51 & 50.46 & 26.04 & 21.45 & 47.84 & 46.78 & 0.16 & 0.15 \\
\hline 2040 & 39.0 & 11.61 & 7.19 & 56.33 & 52.59 & 28.89 & 23.57 & 49.07 & 47.72 & -0.03 & -0.02 \\
\hline 2045 & 42.0 & 12.25 & 7.21 & 58.64 & 54.26 & 30.67 & 24.67 & 50.66 & 49.04 & 0.08 & 0.09 \\
\hline 2050 & 45.0 & 12.92 & 7.23 & 60.48 & 55.40 & 31.85 & 25.15 & 51.99 & 50.12 & 0.12 & 0.16 \\
\hline
\end{tabular}

